\title{
Local and Organic Food Distribution Systems: Towards a Future Agenda
}

\author{
Yinef Pardillo Baez \\ Department of Supply Chain and Operations Management, \\ School of Engineering, Jönköping University, Jönköping 55318 Sweden \\ Email: yinef.pardillobaez@ju.se (Corresponding Author)

\section{Movin Sequeira} \\ Department of Industrial Product development, Production and Design, \\ School of Engineering, Jönköping University, Jönköping 55318 Sweden \\ E-mail: movin.sequeira@ju.se \\ Per Hilletofth \\ Department of Industrial Product development, Production and Design, \\ School of Engineering, Jönköping University, Jönköping 55318 Sweden, \\ E-mail: per.hilletofth@ju.se \\ Department of Industrial Engineering and Management, \\ University of Gävle, SE-801 76, Gävle, Sweden, \\ E-mail: prof.p.hilletofth@gmail.com
}

\begin{abstract}
There has been an increasing consumer demand for local and organic food as they are considered to be more sustainable, ecological, and healthier. The 'conventional' long food distribution system is not sufficient to fulfill the current needs. Consequently, short distribution systems for local and organic food have been gaining popularity, which is not only sustainable but also contributes to food security and satisfies local consumer demand. One such short distribution systems are Alternative Food Networks (AFNs). The AFNs have emerged as a promising provisioning system for local and organic food that promotes economical, environmental, and social sustainability and respect for farming tradition. However, the AFNs are facing challenges in increasing the distribution of local and organic food in the long term. The purpose of the paper is to make a review of the existing short food distribution systems for local and organic food and also to propose a research agenda. In order to achieve this, a literature review is conducted and different food distribution channels within AFNs are studied. The challenges for each food distribution channel are identified and then compared to 'conventional' distribution systems. The main finding of the study is a framework of the main challenges of short food distribution channels within AFNs. The practical implication is generic criteria to consider while designing a short food distribution system that closely connects consumers and farmers of local and organic food. The policy implication is to create favorable conditions to encourage short food distribution systems in the long term.
\end{abstract}

Keywords: food distribution system, alternative food networks, distribution channels, sustainability, localness, local food.

\section{INTRODUCTION}

The food industry is central to human beings and heavily impacts the lives of the entire society. Over the years there has been an increasing demand for food sources due to population growth and increasing urbanization. To put things in perspective, at the current rate of population increase, it is estimated that the world population which is currently 7.3 billion is expected to reach 8.5 billion by 2030 , and extrapolating the trend will reach 9.7 billion by 2050 and 11.2 billion in 2100 (UN Department of Economics, 2015). Therefore, this will pose a direct threat to the availability of food sources or food security, increasing pressure on the entire food supply chain (FSC). Hunger and malnutrition are still major problems in developing countries, which is a large portion of the world (FAO, 2017). Furthermore, this also places a higher burden on limited natural resources such as fresh water, land, and energy (Dobbs et al., 2011). Besides, climate change is increasingly impacting food production across the globe (Schmidhuber \& Tubiello, 2007). Even with this situation, one-third of the food produced on the planet is never consumed, and it became food waste. The main reasons are inadequate logistics and technology, or poor management of food on the part of end-users (Gascón, 2018). Therefore, to avoid these issues and most importantly to ensure food security, the FSC has been one of the important research areas within the broader field of supply chain management (Mahajan et al., 2017). It is possible to affirm that there is growing attention in industry and academia for the food supply chain management (FSCM) (Akkerman et al., 2010; Jonkman et al., 2019; Tsolakis et al., 2014). 
The term FSCM appears to be defined by various authors with little consensus (Mahajan et al., 2017). In simple terms, the FSCM is described as all the conventional processes from 'farm to fork' or from 'plough to plate' (Bourlakis \& Weightman, 2004). The FSCM is a managed process using a combination of skills and knowledge spanning multi-disciplinary domains coming together in a legal framework of minimum standards and basic rules. They are product specific and have their own characteristics, moreover, they have complex features that pose different challenges in their supply chain (Mahajan et al., 2017). The globalization of the FSC has been able to increase overall production of food in the past decades; however, the food becomes expensive, less fresh, less environmentally friendly and puts increasing pressure on farmers from the retailers (Feldman et al., 2015; Martinez et al., 2010). The hegemonic FSC model is characterized by its organizational complexity and the enormous distances traveled by foods and the agricultural supplies used to produce them (Gascón, 2018). This type of conventional FSC can mass-produce food but is still insufficient to meet the rising demand.

Consumers traditionally have based their food choice on factors such as price and quality. However recently, factors related to perceived public benefits such as sustainability are increasingly influencing the decision to buy food (Gracia et al., 2012; Grunert, 2006). Furthermore, consumers have increased their preferences for local, organic and seasonal food (Feldmann \& Hamm, 2015; Gracia et al., 2012; Levidow \& Psarikidou, 2011; Yue \& Tong, 2009), based on social welfare such as reductions in food miles, improving environmental quality, public health and social efficiency (Berg and Preston, 2017). Therefore, local food is increasingly promoted (Ilbery \& Maye, 2005; Horst et al., 2016),

Local food encourages large and small-scale farming to turn to direct markets (Brinkley, 2017). Locally produced food reduces transport and provides the opportunity to generate income in the local community (DEFRA, 2002). Despite the short distances involved, farmers generally use complex marketing channels (Engelseth, 2015). Local food is gaining popularity and is expected to change consumers and farmers (Brinkley, 2017), while it can also alleviate fears about food safety (O'Neill, 2014). Therefore, consumer advocates and policymakers are pursuing policies that favor local food production based on motives such as environmental quality, public health, and local economic development (Berg and Preston, 2017). There is a shift from conventional FSC to a more local approach, that is sustainable and reduces the agricultural impact on the environment (Renting et al., 2003). This has given rise to alternative or shorter food supply chains.

The alternative food supply chains, or otherwise known as Alternative Food Networks (AFNs), are defined as a newly emerging network of farmers, consumers, and other actors that use alternative methods of supplying food to the consumer (Murdoch et al., 2000). The term AFN is also used synonymously to Short Food Supply Chain (SFSC). They are a response to the dominant industrial food system that distances and detaches food production from food consumption (Venn et al., 2006). The important advantages of these AFNs that provide local food are high quality (fresh, healthy, nutritious), cheap, safe, sustainable and it supports the local economy (Feldman et al., 2015; Gracia et al., 2012;
Martinez et al., 2010). Moreover, AFNs attempt to reconfigure relationships between food producers and consumers (Marsden et al., 2000; Renting et al., 2003; Venn et al., 2006), where the consumers can have face-to-face interactions with the farmers who produce their food leading to transparent and trust-based relationships (Hendrickson \& Hefferman, 2002; Levidow \& Psarikidou, 2011; Smithers \& Johnson, 2004). This leads to social embeddedness what is often seen as an advantage for AFNs or local food systems (Gracia et al., 2012; Hinrichs, 2000). There is sufficient evidence of sustainability impacts of these alternative food supply chains and without these measures, it would be much difficult to achieve the UN goals of sustainability (UNSD, 2016).

Some researchers show that there are more and more farmers who want to sell their products directly (Levidow \& Psarikidou, 2011). The emerging pattern of creation, operation, and evolution of AFNs is one of the key factors of improving the local economy and directly connecting the farmers to the consumers. Such networks are also being classified based on a range of socially constructed food quality criteria (Marsden, 1998). When in competition with conventional food supply chains, the logistics and best practices from the conventional supply chains can be transferred to local food supply chains to improve the efficiency and effectiveness (Mittal et al., 2018). However, the AFNs are facing a challenge to maximize the distribution of local and organic products in the long term (Pardillo-Baez et al., 2019). Furthermore, according to (Siegner et al., 2018), little is understood about where and how farmers distribute their food including modes of transportation delivery (either individually or in aggregate), and to whom (retail, institution, anti-hunger programs). As Manikas et al. (2019) remark, additional research is needed to fully explore the exciting possibilities that exist for local food producers in today's food industry. Therefore, the purpose of this paper is to make a review of the existing short food distribution systems for local and organic food and propose a research agenda. The purpose is fulfilled through two research questions: (1) "What are the challenges associated with different channels in the alternative food network?"; and, (2) "How can these challenges be dealt with?". In order to achieve this, a literature review on short food distribution systems is conducted and different food distribution channels within AFNs are studied.

The remainder of the paper is structured as follows. To begin with, a theoretical background of Short Food Supply Chains (SFSCs) and AFNs are presented in Section 2. Thereafter, the methodology of the research is presented in Section 3. After that, the findings from the review are presented in Section 4. Thereafter, the findings are discussed in Section 5, then finally the research is concluded in Section 6 respectively.

\section{THEORETICAL BACKGROUND}

\subsection{Short Food Supply Chain (SFCs)}

The concept of SFSCs, according to Galli et al. (2013), emerged at the turn of the century in the context of the broader debate on alternative food chains, alternative food networks or sustainable food chains; due to the trend of global value chains dominated by retailers in the agro-food system. SFSCs have been increasingly considered by the 
industry, civil society organizations, decision-makers, and policy in government (Galli et al., 2013). Renting et al. (2003) suggest that the SFSC concept is more specific than AFNs, and, rather, covers the interrelations between actors who are directly involved in the production, processing, distribution, and consumption of new food products. Galli et al. (2013) suggest that SFSC is an alternative type of governance and organization of food chains that plays an increasingly important role in food supply networks. They also mentioned that the two basic criteria that define SFSCs are their physical and social proximity; where there are no or very few intermediaries in SFSCs; that make them more flexible and adaptable to new situations and consumer needs (Galli et al., 2013). However, in comparison to global food chains, one limitation of SFSC is the limited supply of a varied range of food, mainly due to the natural seasonality of products. But some researchers emphasize the rise in interest from the customer side in seasonal food and continued growth of demand for organic products (Levidow \& Psarikidou, 2011), which may reduce the impact of this limitation of SFSC.

The SFSCs in academic literature can be seen as the reterritorialization, re-localization, re-spatialization and reconnection of the supply chains into "short circuits", likewise as AFNs (Allen et al., 2003; Kneafsey et al., 2013; Levidow \& Psarikidou, 2011; Manikas et al., 2019). The SFSCs are varied in nature and practice and exist all over the world in a wide variety of forms, in both commercial and non-commercial settings (Galli et al., 2013). The SFSCs offer a more diverse variety of products in some regions although dependent on the season (Galli et al., 2013; Edwards-Jones, 2010). SFSCs give farmers a channel tailored to small quantities and high/special quality, which are nevertheless appreciated on the market.

There are three categories of SFSCs: face-to-face, proximate, and spatially extended (Marsden et al., 2000; Renting et al., 2003). The first category "face-to-face SFSCs" is based on face-to-face interactions, as a mechanism for aligning producer-consumer networks. Personal interaction and trust are the foundations in this category, and the food is sold directly to the consumer by the producer (Renting et al., 2003). The second category "proximate SFSCs" is based on the relation of proximity (region or place). This category requires more complex regulations. The third category "spatially extended SFSCs" based on extended relations in time and space; the products can be sold to costumers outside the region (national markets). This category is still 'short' in despite a long distance is due to the awareness that connects the consumer (Renting et al., 2003). The interest in SFSCs and AFNs is growing due to their potential to contribute to more sustainable food systems, rural development, and healthier communities.

\subsection{Alternative Food Networks and Distribution Channels}

An extensive literature developed on Alternative Food Networks (AFNs) has been a subject of considerable interest in recent decades (Bos \& Owen, 2016; Tregear, 2011). AFNs are a comprehensive body of practices related to food provisioning, from different forms of organization in the agri-food system, that promote a sustainable and civil economy, environment, biodiversity and respect for tradition (Timpanaro et al., 2018; Tregear, 2011; Barbera \& Dagnes., 2016). According to O`Neill (2014) and Renting et al. (2003) the alternative and local food systems have been a means of adding value to local economies and capitalizing on consumer demand for local quality food. The AFNs are different from the mainstream food systems, and are characterized by a short production and distribution chain, integrating dimensions of spatial, economic, and social proximity (Barbera \& Dagnes, 2016; Tregear, 2011). They are seen as seeds of social change, which allow actors to rework power and knowledge relationships, especially through social and physical proximity between producers and consumers (Allen et al., 2003; Feagan, 2007; Levidow \& Psarikidou, 2011). However, Bos \& Owen (2016) argue that AFNs are situated alongside and operate within conventional systems and market logic. In line with this, O’Neill (2014) highlighted that alternative and local food systems interact with the conventional food system in complex and multiple ways. Due to this hybridity, AFNs have been unable to coalesce around any consistent, normative content of their own (Bos \& Owen, 2016; Renting et al., 2012).

The main aim of AFNs is to be economically viable for farmers and consumers, use ecologically production and distribution practices, and enhance social equity and democracy for all members of the community (Feenstra, 1997; Tregear, 2011). The farmers and consumers take the central role and make the AFNs a self-organized system with very little involvement from institutions (Barbera \& Dagnes, 2016). The farmers and consumers are reconnected through a short distance, transparency, and localization of the supply chain (Bos \& Owen, 2016). In this context, Dowler et al. (2010) define 'reconnection' as bringing together different elements of the food system. The circuits of food production and consumption are organized locally and independently, which makes the AFN associated with a particular region (Dansero \& Puttilli, 2014). Venn et al. (2006) in their study enumerate four parameters or attributes of AFNs that have been highlighted by research and empirical papers. Those attributes are the attempt to connect consumers, producers, and food in a new economic space which re-embeds food production and consumption; the non-conventional supply distribution detached from industrial supply and demand distribution and corporately controlled; adopted principles of social embeddedness founded on the principles of trust; and based around a notion of quality preserving traditions and heritage.

The AFNs can be presented in different forms such as: farmers' markets, community supported agriculture (CSA), box schemes, farm shops or on farms sales, consumer cooperatives, direct internet sales, community gardening, grow-your-own (GYO), roadside sales, home deliveries, regional hallmarks, certification labels, production codes and others (Adams \& Adams, 2011; Barbera \& Dagnes, 2016; Bos \& Owen, 2016; Galli et al., 2013; Jarosz, 2008; Levidow \& Psarikidou, 2011; Renting et al., 2003). These forms of AFNs can be grouped into the three categories of SFSCs: face-to-face SFSCs, proximate SFSCs, and spatially extended SFSCs (Table 1). 
Table 1 Forms of Alternative Food Networks (AFNs) by categories of SFSCs (adapted from Galli et al., 2013; Renting et al., 2003)

\begin{tabular}{|c|c|c|}
\hline Face to Face & Proximate & Extended \\
\hline Farm shops & Farm shop groups & Certification labels \\
\hline Farmers markets & Regional hallmarks & Production codes \\
\hline Roadside sales & Consumer cooperatives & Reputation effects \\
\hline Pick your own & Community supported agriculture (CSA) & \\
\hline Box schemes & Thematic routes (articulation in space) & \\
\hline Home deliveries & Special events, fairs (articulation in time) & \\
\hline Mail order & $\begin{array}{l}\text { Local shops, restaurants, tourist enterprises dedicated retailers (ex, } \\
\text { whole food, specialty, or dietetic shops) }\end{array}$ & \\
\hline E-commerce / direct internet sales & Catering for institutions (canteens, schools) & \\
\hline Farm to work (training component) & Sales to emigrants & \\
\hline Mobile urban farm & Community supported fishery & \\
\hline Consumers as producers & A combination of consumer coops and CSA & \\
\hline Solidarity-based purchasing groups & On farm vending machines & \\
\hline Direct sales by farmers & Alternative grocery (e.g., health food) stores & \\
\hline \multicolumn{3}{|l|}{ Consumer cooperatives } \\
\hline \multicolumn{3}{|l|}{ Community gardening } \\
\hline \multicolumn{3}{|l|}{ Grow-Your-Own (GYO) } \\
\hline \multicolumn{3}{|l|}{ Solidarity-based purchasing groups } \\
\hline \multicolumn{3}{|l|}{ On-farm direct sales by farmers } \\
\hline \multicolumn{3}{|l|}{ Off-farm direct sales by farmers } \\
\hline \multicolumn{3}{|l|}{ Traditional local markets } \\
\hline \multicolumn{3}{|l|}{ Fair trade groups } \\
\hline Wild food foraging & & \\
\hline
\end{tabular}

Hempel and Hamm (2016) indicate that in the farmers' markets the food is sold mainly locally, while Levidow and Psarikidou (2011) affirm that the farmers' markets and onfarm shops complement each other, due to attracting similar consumers who recognize quality from familiar and trusted suppliers. Brinkley (2017) argues that farmers' markets are the most common practices for wholesale distribution and direct distribution to consumers. Farmers' markets aim to bring producers and consumers together under direct marketing schemes (Brown, 2001; Kirwan, 2006; Fendrychová \& Jehli`cka, 2018).

Another way to bring food to the markets is through agro-food hubs (Manikas et al., 2019). These agro-food hubs are defined as an alternative sustainable channel of distribution and value creation that facilitates the synergies among agricultural SMEs; moreover, there is little systematic research exists regarding alternative channels of distribution for farm SMEs (Manikas et al., 2019).

Other ways to bring local and organic food to the market is through box schemes, community supported agriculture and solidarity-based purchasing groups (Barbera \& Dagnes, 2016; Brown et al., 2009). These are labelled as innovative practices (Barbera \& Dagnes, 2016). More traditional practices that exist are on and off-farm direct sales by farmers and traditional local markets. According to Manikas et al. (2019), smallholders and family farming is a key element of the European model of agriculture; and there is a significant need to create viable economic alternatives to the existing agricultural system dominated by SMEs. AFNs many times are integrated by farm SMEs and represent a way to bring locally produced food to the market.

The distribution channel acts as a circuit through which the products travel from producer to consumer, and they are different for the different forms of AFNs. Hence, the corresponding food distribution systems, which make the products and services available to the consumer may vary according to the food distribution channel of the form of AFN. For example, when considering AFNs forms categorized as "face-to-face", the distribution channel is direct; for the "proximity", the distribution channel can be a short or retailer channel; and for "extended", the distribution channel is usually a large or wholesaler channel. However, Heffeman (1998), Howard (2009) and Brinkley (2017) consider that only a few global corporations control distribution, connecting consumers to producers. Nie and Zhang (2017) affirm that traditional opinions suggest that a direct channel is better than an indirect channel for manufacturers to sell their products. Some limitations appear in direct channels, such as facing contradictory policies, which espouse benefits of local food but relegate all responsibility to market actors; but at the same time as a benefit, farmers can gain premium prices and closer relations to consumers (Levidow \& Psarikidou, 2011).

\section{METHODOLOGY}

The methodology used in the research is a literature review. According to Snyder (2019), the literature review is considered as a research method. The literature review has been developed by using a seven-step model of the comprehensive literature review (CLR) to incorporate rigour, validity and reliability. The seven-step model offers a tool that can be used to inform the various components of the primary research study (Onwuegbuzie \& Frels, 2016). For this literature review, the three phases of the seven-step 
model have been utilized (exploration, interpretation, and communication). The steps followed in the exploration phase are: 1. Exploring beliefs and topics; 2. Initiating the search; 3. Storing and organizing information; 4. Selecting/deselecting information; 5. Expanding the search to include more media, observations, documents, experts, secondary data or sources. The step followed in the interpretation phase is: 6. Analyzing and synthesizing information. Finally, the step followed in the communication phase is: 7. Presenting the CLR report.

Some adaptations have been included because the paper is an ongoing research and, in the future, more data will be collected. Therefore a cyclical process will be followed, with the intention of continuous improvement of the results. The methodology process and the status for each step are shown in the figure below (Figure 1).

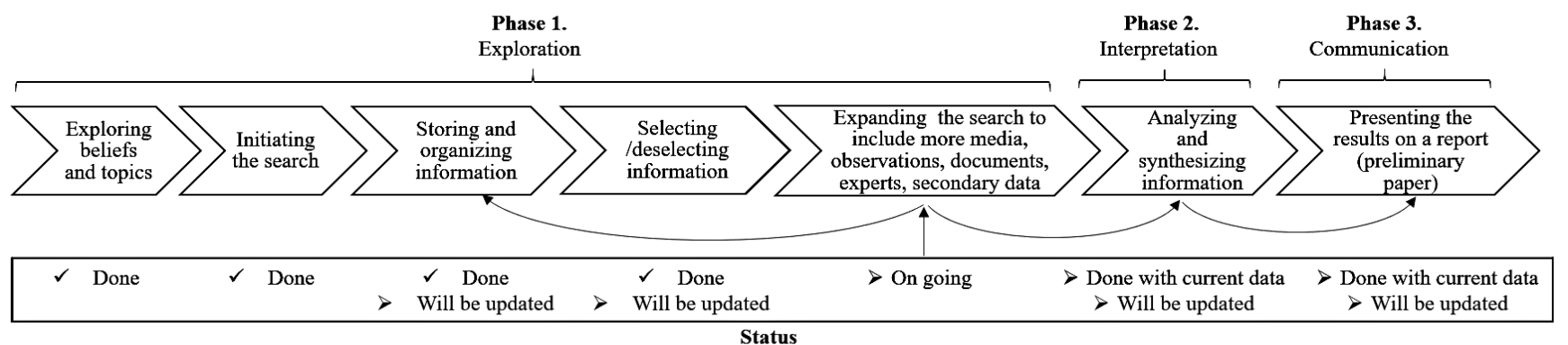

Figure 1 Methodology process and status of the current research

\section{FINDINGS}

When studying the literature, some demands for the AFNs can be identified: environmental, social, economic and health and well-being. Some of the AFNs like farmer markets (Freedman et al., 2011; Ruelas et al., 2012) and grow-your-own (Corrigan, 2011; Kortwright \& Wakefield, 2011) have shown some increase aspects of access to healthy food, but in general, the evidence of effects on access to healthy food is limited to its quantity and quality. However, the AFNs have increased the knowledge about food amongst consumers and leads to the adoption of a healthier diet (Galli et al., 2013). Freidberg \& Goldstein, (2011), pointed out that researches should focus not only on the quality of food but also on building alternative food supply networks. The distribution channels of AFNs represent a way to bring food to the markets, but there are challenges associated with it. The challenges that were identified ( 23 in total) as a result of the review, appear listed in Table 2.

Table 2 Challenges in the AFNs' distribution channels

\begin{tabular}{|c|c|c|}
\hline No. & Challenges & Source \\
\hline 1. & Meeting the rising demand for food in quantity. & Accorsi et al., 2016 \\
\hline 2. & $\begin{array}{l}\text { Meeting the increasing demand for organic, welfare-friendly and } \\
\text { locally produced food. }\end{array}$ & $\begin{array}{l}\text { Bosona et al., 2011; Kroma, 2006; Marsden \& Smith, } \\
\text { 2005; Gracia et al., 2012; Levidow \& Psarikidou, } 2011\end{array}$ \\
\hline 3. & $\begin{array}{l}\text { Meeting the rising demand for high quality, transparency in food } \\
\text { production and traceability of seasonal or locally produced food }\end{array}$ & $\begin{array}{l}\text { Bosona et al., 2011; Hempel \& Hamm, 2016; Levidow } \\
\text { \& Psarikidou, } 2011\end{array}$ \\
\hline 4. & $\begin{array}{l}\text { Maximizing the distribution of local and organic products in the long } \\
\text { term. }\end{array}$ & Figueroa-Rodríguez et al., 2019, Wittman et al., 2012 \\
\hline 5. & Optimization in route distance and delivery time for producers & Bosona et al., 2011 \\
\hline 6. & Keeping the availability of products. & $\begin{array}{l}\text { Berg \& Preston, 2017; Figueroa-Rodríguez et al., } \\
\text { 2019, Wittman et al., } 2012\end{array}$ \\
\hline 7. & Supply that allows a variety of products. & Figueroa-Rodríguez et al., 2019, Wittman et al., 2012 \\
\hline 8. & Limited growing season and unpredictable weather patterns & Wittman et al., 2012 \\
\hline 9. & $\begin{array}{l}\text { Guaranteeing optimal pricing of local and organic food products by } \\
\text { creating viable economic alternatives, which mean fair compensation } \\
\text { for farmers and attractive prices for consumers }\end{array}$ & $\begin{array}{l}\text { Barbera \& Dagnes, 2015; Berg \& Preston, 2017; } \\
\text { Figueroa-Rodríguez et al., 2019, Wittman et al., } 2012\end{array}$ \\
\hline 10. & $\begin{array}{l}\text { Finding solutions for logistic cost as a bottleneck for small and local } \\
\text { food producers; decrease distribution and additional investments } \\
\text { cost as a key factor for economic success }\end{array}$ & Bosona et al., 2011; Galli et al., 2013 \\
\hline 11. & Accessibility in terms of location & Wittman et al., 2012 \\
\hline 12. & Accessibility in terms of hours and days of operation & $\begin{array}{l}\text { Berg \& Preston, 2017; Figueroa-Rodríguez et al., } \\
\text { 2019; Gumirakiza et al., 2014; Hofmann et al., 2009, } \\
\text { Wittman et al., } 2012\end{array}$ \\
\hline
\end{tabular}


Table 2 Challenges in the AFNs' distribution channels (cont')

No.

Challenges

Source

13. Reducing distance and time for the customer access to the market

Figueroa-Rodríguez et al., 2019; Gumirakiza et al., 2014; Hofmann et al., 2009

14. Controlling the distribution connecting consumers to producers.

Martinez et al., 2010

15. Ensuring good communication practices among actors to solve

specific difficulties in complying with regulations

Galli et al., 2013

Availability of infrastructure, capacity, equipment, acceptable

16. inspection status, and human/financial capital on the distribution

16. channel to meet demand requirements for local and organic food

Martinez et al., 2010; Levidow \& Psarikidou, 2011 (availability of strong local food chains)

17. Impacts of different governance systems, including the role of local authorities and policies

18. Closely connections and transparent and trust-based relationships between consumers and farmers of local and organic food

Galli et al., 2013; Levidow \& Psarikidou, 2011

Barbera \& Dagnes, 2016; Hendrickson \& Hefferman, 2002; Levidow \& Psarikidou, 2011; Smithers \& Johnson, 2004

19. Transferring logistics and best practices from the conventional supply chains to improve efficiency and effectiveness.

Mittal et al., 2018

20. Competition from the conventional food system

Wittman et al., 2012

Bringing positive contribution to the ecosystem, biodiversity and

21. landscape, local employment, fair trade and social justice in sustainable food production, distribution and consumption

Bosona et al., 2011; Coley et al., 2009; Jarosz, 2008; O’Neill, 2014.

22. Farmers distributing their products to those in need while maintaining their operations

Finding the intermediaries able to cope with alternative forms of

23. production, and reconnecting producers of local and organic food with more consumers.

Biewener, 2016; Daftary-Steel et al., 2015; Siegner et al., 2018

Levidow \& Psarikidou, 2011; Venn et al., 2006

In order to comprehend the above listed challenges, they have been grouped into seven categories corresponding to wider operations strategy: efficiency, sustainability, quality, flexibility, communication, technology, and innovation. Efficiency challenges are those that have implications on fulfilling demands with optimum resources. Sustainability challenges have implications on being economic, social, and environmentally sustainable. Quality challenges have implications for providing high-quality products and/or services. Flexibility challenges have implications on adjusting according to consumer's requirements and needs. Communication challenges have implications for transferring information and/or knowledge between actors of distribution channels. Technology challenges have implications for using existing or new technology. Innovation challenges have implications for introducing updated and novel products and/or services. Table 3 shows the classification for each challenge. Each challenge can also be classified into more than one category. The challenges 2, 3, 4, 6, 18, 19 and 23 have implications in highest number of categories. The category with most challenges is efficiency (19), followed by sustainability (12), followed by flexibility and innovation (11 each).

Table 3 Classification of the challenges for the AFNs distribution channels

\begin{tabular}{|c|c|c|c|c|c|c|c|c|c|c|c|c|c|c|c|c|c|c|c|c|c|c|c|}
\hline \multirow{2}{*}{ Classification } & \multicolumn{23}{|c|}{ Challenges } \\
\hline & 1 & 2 & 3 & 4 & 5 & 6 & 7 & 8 & 9 & 10 & 11 & 12 & 13 & 14 & 15 & 16 & 17 & 18 & 19 & 20 & 21 & 22 & 23 \\
\hline Efficiency & $X$ & $\bar{X}$ & & $\bar{X}$ & $\bar{X}$ & $X$ & $x$ & & $X$ & $X$ & $X$ & $\mathrm{X}$ & $x$ & $\bar{X}$ & $\bar{X}$ & $X$ & $X$ & & $\mathrm{X}$ & $\mathrm{X}$ & $X$ & $\bar{X}$ & $\bar{X}$ \\
\hline Sustainability & $X$ & $X$ & & $X$ & $X$ & $X$ & $X$ & $X$ & & & & & $x$ & & $X$ & & $X$ & $X$ & & & $X$ & $X$ & \\
\hline Quality & & $X$ & $X$ & & & & & & & & & & & $X$ & & & & & & & & & \\
\hline Flexibility & & & & & & $X$ & $x$ & $x$ & & & $X$ & $X$ & $x$ & & & & & $x$ & $X$ & $x$ & & $X$ & $x$ \\
\hline Communication & & & $X$ & & & & & & & & & & & $x$ & $x$ & & $x$ & $x$ & & & & & $x$ \\
\hline Technology & & & $X$ & $X$ & & & & & & $X$ & & & & & & $X$ & & & $X$ & & & & \\
\hline Innovation & & $X$ & $X$ & $X$ & $X$ & $X$ & & & $X$ & $X$ & & & & & & & & $X$ & $X$ & $x$ & & & $X$ \\
\hline
\end{tabular}

In order to deal with the challenges, an analysis of the impact of the challenges is needed. The challenges can have different impacts depending on the types of AFNs' distribution channels. Each challenge is assigned an impact level for the corresponding form of AFN: face-to-face, proximate, and extended. The impacts have been assigned into three levels: low level, medium level and high level. If the impact of a challenge is low level, then it means that less work is required from the actors of the distribution channel. Meanwhile, if the impact of challenge is high level, then it 
measn that more work from the actors of the distribution channels is required to deal with it. A graph is plotted to visualize the impact level of the challenge for the corresponding form of AFN (Figure 2).

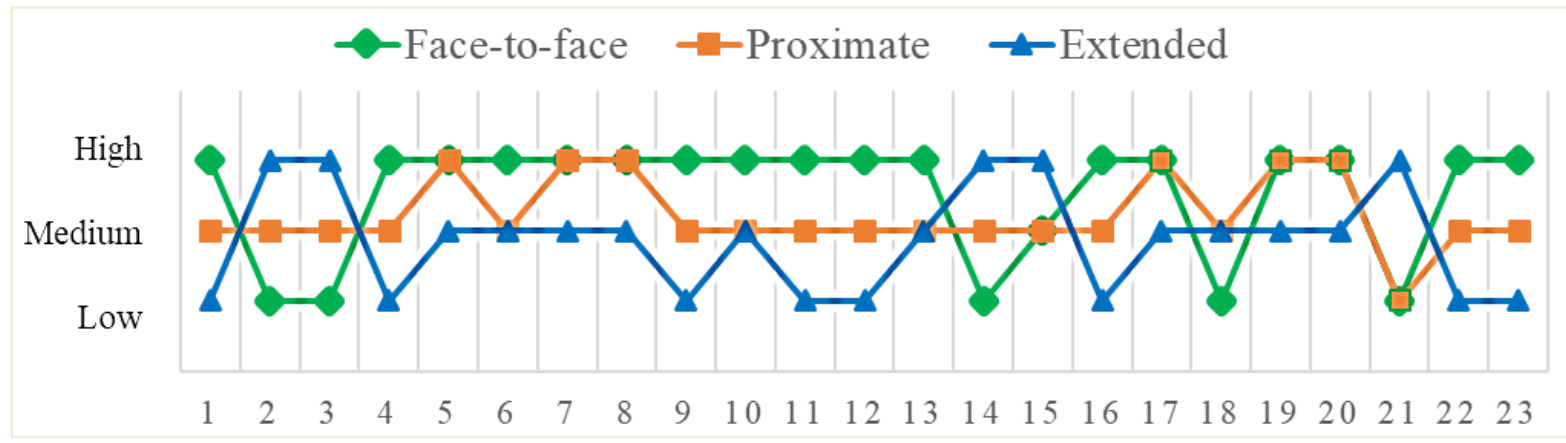

Figure 2 Challenges impact level on form of AFNs

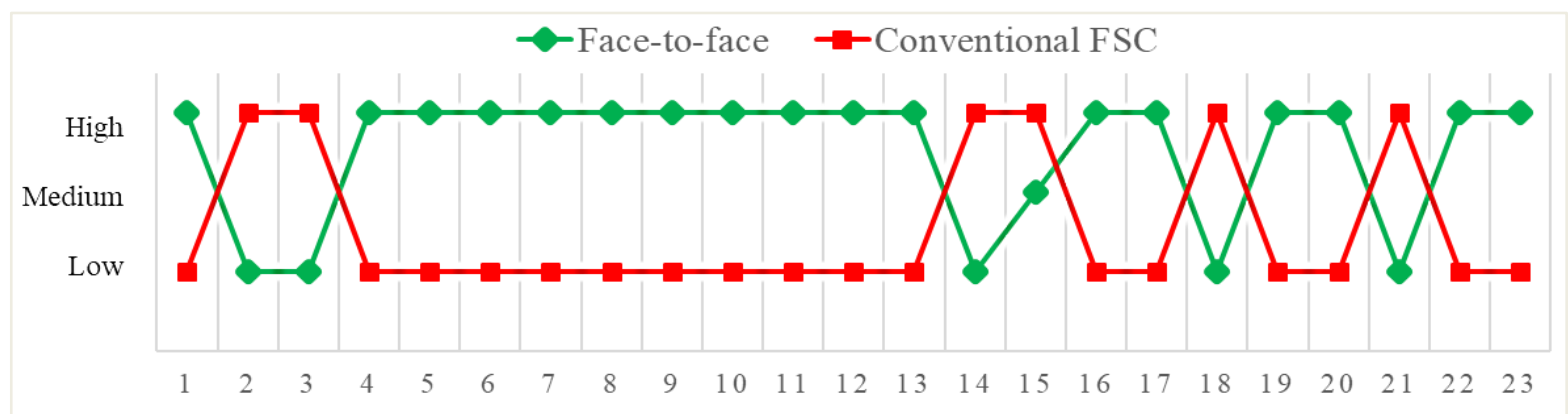

Figure 3 Challenges impact level on face to face and conventional FSC distribution channels

It is possible to affirm that the higher impact of challenges is mostly presented on the face-to-face form for AFNs. For a conventional distribution channel for FSC, the behavior of the curve will be opposite to that of the face-toface distribution channels as shown in Figure 3.

The challenges' impact level on the conventional FSC distribution channels is usually low when compared with the challenges' impact level on the face-to-face distribution channels. The main reason is that conventional FSC distribution channels have better capabilities to deal with the challenges, and therefore its impact is lower. On the other hand, the face-to-face distribution channels do not have all conditions and therefore the impact level of the challenge is high. This suggests that more resources are needed for the face-to-face distribution channel. For a few of the challenges, the impact is low for face-to-face distribution channels. The main reason for this is their ability to operate with local and organic food closely connected to consumers, which is more complex for the conventional FSC distribution channels.

\section{DISCUSSION}

The results suggest that there is a higher level of impact of challenges on the face-to-face forms of distribution channels for AFNs. Seventeen challenges were identified which has a higher impact on face-to-face distribution channels as compared to six challenges on conventional ones. The challenges have also impact across several categories. From the seven challenges with implications in more categories, the higher impact is found in four of them $(4,6,19,23)$ for the face-to-face distribution channels and in three of them $(2,3,18)$ for the conventional distribution channels. The higher impact challenges with implications in more categories for the face-to-face distribution channels are the ones that imply that more work is required from the actors of the distribution channels in order to deal with them These challenges are the distribution of local and organic products in the long term (4); keeping the availability of products (6); transferring logistics and best practices from the conventional supply chains to improve the efficiency and effectiveness (19); and finding the intermediaries able to cope with alternative forms of production, and reconnecting producers of local and organic food with more consumers (23).

On conducting this review, it is possible to affirm that very little scholarly data exists on distribution channels for the accessibility of local and organic food. Therefore, more work is also needed from the academic side in order to support and lead the actors of the distribution channels. Even when the challenges have been identified, more research is needed to validate them, and find the requirements for the distribution channels that may bring local and organic food according to consumers' and farmers' desires (Pardillo-Baez et al., 2019).

A research agenda is proposed, which address the directions for future research and their priorities. Twentyseven directions have been proposed based on the studies from the literature review (Table 4), and five based on the own considerations of the authors (Table 5). The directions for future research have been evaluated according to two criteria; the level of importance and the term (the time period of study). The level of importance is classified as high (1), medium (2), or low (3) depending on the authors' assessment. The term is classified as long (1), medium (2), or short (3), depending on the time needed to work with the task, which is related to the task's complexity. The priority is calculated as a product of the level of importance and term The priority can get values from 1 to 9 , while smaller values will indicate higher priorities from the authors' perspective. 
Table 4 Research agenda base on researchers' criteria

No.

Directions for Future Research

References

Level of Importance

Term (Time to Work With)

Figueroa-Rodriguez et al., 2019; O'Neill,

2014; Venn et al., 2006; Brinkley, 2017;

Levidow \& Psarikidou, 2011

Broadening the conceptualization of AFNs and typology of different alliances of local food systems

A continued review focusing only on the latest contributions under a systemic view in order to increase our contemporary knowledge of

AFNs and to update the existent challenges for their distribution channels.

Figueroa-Rodriguez et al., 2019

Medium Low

(1) (2)

(3)

(1)

Priority

2

de ecosystem boundaries and including other flows, such

3. as the production and supply of packaging materials and modeling disposal of food waste.

Accorsi et al., 2016

2

2

Consider a what-if multi-scenario analysis to identify the right balance

4. of small and global intensive agro-food systems and assess the factors, affecting the economic and environmental sustainability of

Accorsi et al., 2016

2 food supply chains.

5. Using case studies of larger sizes

Jonkman et al., 2019; Renting et al.,

2003; Venn et al., 2006

1

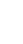

6. Present Supply Chain design models tailored to applications in the context of Agro-food supply chain

Jonkman et al., 2019

2

2

4

Tools across disciplines in order to design cost-effective agro-food

7. supply chains that proactively consider environmental externalities (weather and soil conditions)

8. Integrated optimization of distribution channel for highly perishable local foods and face-to face AFNs

Accorsi et al., 2016; Renting et al., 2003

1

2

2

Generic method for perfomance measurement of Agro-food hubs and evaluation of success/failure

Jonkman et al., 2019; Bosona et al., 2011

1

Manikas et al., 2019

2

2

2

Barbara \& Dagnes, 2016; Levidow \&

Psarikidou, 2011; Figueroa-Rodriguez et al., 2019; O'Neill, 2014; Venn et al., 2006

10. How AFNS can
with each other

Barbara \& Dagnes, 2016

1

2

2

4

wifferent AFNS can collaborate with each other to overcome their challenges

12. Study the role of social media on consumers sustainable behaviour and its impact on AFNs

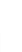

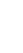


Table 4 Research agenda base on researchers' criteria (cont')

No.

Directions for Future Research

\section{References}

Level of Importance

Term (Time to Work With)

Nirections for Future Research

13. Study the motivations of consumers for shopping at farmers' markets.

Figueroa-Rodriguez et al., 2019; Howard,

2009

High Medium Low

(2)

(3)

Long Medium (1) (2)

3)

\section{Priority}

2

24

Study how citizens participate in sustainable and participatory food

14. practices in different geographical localities? Understanding

Bos \& Owen, 2016; Bosona et al., 2011; consumer's perception of local food Brown et al., 2009; Gracia et al., 2012

15. Study how make consumers taking responsibility for food choices that

2

2

4 enhance sustainability within food markets?

Levidow \& Psarikidou, 2011

16. Exploring new theoretical considerations to explain how social relationships impact local food networks.

Brinkley, 2017

Levidow \& Psarikidou, 2011; FigueroaRodriguez et al., 2019; O'Neill, 2014

17. Include in the study of AFNs the need of intermediaries and their classification.

Study the role of policy makers and the policies that standarize,

18. facilitates and promote the development of food supply on the region; and make them clear and aligned for AFNs. Public policies leading to connect local farmers with alternative food networks

Consider the support for producer cooperation (collaborative working),

19. co-operative ventures to reduce product miles and increase availability and productivity of local products

20. Impact of local food on rural-urban interactions

21. Identifying gaps in local food networks

Levidow \& Psarikidou, 2011; Brinkley,

2017; Figueroa-Rodriguez et al., 2019; O'Neill, 2014; Howard, 2009

Levidow \& Psarikidou, 2011

Bosona et al., 2011

1

3

2

Brinkley, 2017

1

2

Gascon, 2018

3

1

2

23. hours, parking, product availability and pricing that have obvious

relevance for consumers and to proposals for expanding local food availability

24. Study characteristics of AFNs in different regions

O'Neill, 2014

2

2 
Table 4 Research agenda base on researchers' criteria (cont')

\begin{tabular}{|c|c|c|c|c|c|c|c|c|c|}
\hline \multirow[b]{2}{*}{ No. } & \multirow[b]{2}{*}{ Directions for Future Research } & \multirow[b]{2}{*}{ References } & \multicolumn{3}{|c|}{ Level of Importance } & \multicolumn{3}{|c|}{ Term (Time to Work With) } & \multirow[b]{2}{*}{ Priority } \\
\hline & & & $\begin{array}{l}\text { High } \\
\text { (1) }\end{array}$ & $\begin{array}{l}\text { Medium } \\
\text { (2) }\end{array}$ & $\begin{array}{l}\text { Low } \\
\text { (3) }\end{array}$ & $\begin{array}{l}\text { Long } \\
\text { (1) }\end{array}$ & $\begin{array}{l}\text { Medium } \\
\text { (2) }\end{array}$ & $\begin{array}{c}\text { Short } \\
(3)\end{array}$ & \\
\hline 26. & Study the distribution flows of local produced foods across a city & Siegner et al., 2018 & 1 & & & 1 & & & 1 \\
\hline 27. & $\begin{array}{l}\text { Study the distribution channels for face-to-face AFNs, characterize } \\
\text { and compare them. Identify similarities and differences. How to work } \\
\text { with them and make them more efficient and sustainable? }\end{array}$ & Venn et al., 2006 & 1 & & & 1 & & & 1 \\
\hline
\end{tabular}


Table 5 Research agenda base on own authors' criteria

\begin{tabular}{lllllll} 
& & \multicolumn{2}{c}{ Level of importance } & \multicolumn{2}{c}{ Term (time to work with) } \\
\cline { 3 - 5 } No. Directions for future research & High (1) & Medium (2) & Low (3) & Long (1) & Medium (2) & Short (3)
\end{tabular}

1. Validate the impact of the challenges on the distribution channels for AFNs

\begin{tabular}{l} 
2. $\begin{array}{c}\text { Identify the requirements or } \\
\text { characteristics of the distribution } \\
\text { channels of the AFNs. }\end{array}$ \\
$\begin{array}{l}\text { Identify the advantages and } \\
\text { disadvantages of each distribution } \\
\text { channel on face-to-face AFNs forms. }\end{array}$ \\
$\begin{array}{l}\text { Study the capacity of different places to } \\
\text { develop a local food distribution system }\end{array}$ \\
$\begin{array}{l}\text { Design the distribution system that } \\
\text { closely connects consumers and farmers } \\
\text { of local and organic food, answering their } \\
\text { requirements and allowing efficient and } \\
\text { sustainable development. }\end{array}$ \\
\hline
\end{tabular}

As it was previously indicated, the face-to-face distribution channels are facing the higher impact of the challenges despite having conditions to provide local and organic food to consumers. Even though in total 32 directions for future research were identified, the suggestion is to focus on the seven directions with higher priority for future research. These directions are: using case studies of larger sizes; study how different AFNs can co-exist with the conventional system and collaborate; study the possible intermediaries able to cope with AFNs and classified them; study the distribution flows of locally produced foods across a city; study the distribution channels for face-to-face AFNs identifying similarities and differences and finding how to make them more efficient and sustainable; identify requirements and characteristics of the distribution channels of the AFNs; and designing the distribution system for local and organic food that closely connects consumers and farmers, answering their requirements and allowing efficient and sustainable development.

\section{CONCLUSION}

A review of the existing short food distribution systems for local and organic food has been conducted and a research agenda has been proposed. In total, 23 challenges were identified for the local food distribution channel, and the level of impact for each challenge has been estimated on each group of the AFNs category. A classification of the challenges was done taking into account their implications they may have in efficiency, sustainability, quality, flexibility, communication, technology, and innovation. As a result of this classification, it is possible to affirm that the major implications are in the efficiency with 19 challenges, followed by sustainability with 12 and flexibility and innovation with 11 challenges each one.

After evaluating the impact of the challenges in high, medium, low, it is possible to affirm that the higher impact of challenges is mostly presented on the face-to-face form for AFNs. The opposite situation is faced by conventional distribution channels, which have better capabilities to deal with the challenges, and then the impact is low. To deal with challenges actors need to work more with efficiency, sustainability, flexibility, and innovation.

A general research agenda is suggested with 32 proposed directions for future researches, 27 based on literature review and 5 based on the author's criteria. Moreover, seven of these directions were identified with a high priority it is suggested to focus on them for closer future research. But the main conclusion is that more research is needed on the field of distribution channels for AFNs especially on the direct or face-to-face forms of distribution channels.

\section{REFERENCES}

Accorsi, R., Cholette, S., Manzini, R., Pini, C., Penazzi, S., (2016). The land-network problem: ecosystem carbon balance in planning sustainable agro-food supply chains. Journal of Cleaner Production 112, pp. 158 - 171.

Adams, D. C., \& Adams, A. E. (2011). De-placing local at the farmers' market: consumer conceptions of local foods. Journal of Rural Social Sciences 26 (2), pp. $74-100$.

Akkerman, R., Farahani, P., \& Grunow, M., (2010). Quality, safetyare and sustainability in food distribution: A review of quantitative operations management approaches and challenges. OR Spectrum 32 (4), pp. 863 - 904.

Allen, P.; FitzSimmons, M.; Goodman, M.; Warner, K., (2003) Shifting plates in the agrifood landscape: The tectonics of alternative agrifood initiatives in California. Journal of Rural Studies 19, pp. $61-75$.

Barbera, F., Dagnes, J., (2016). Building Alternatives from the Bottom-up: The Case of Alternative Food Networks. Agriculture and Agricultural Science Procedia 8, pp. 324 331.

Berg, N., Preston, K.L., (2017). Willingness to pay for local food?: Consumer preferences and shopping behavior at Otago 
Farmers Market. Transportation Research Part A 103, pp. $343-361$.

Biewener, C., (2016). Paid Work, Unpaid Work, and Economic Viability in Alternative Food Initiatives: Reflections from Three Boston Urban Agriculture Endeavors. J. Agric. Food Syst. Community Dev. 6, pp. 35 - 53.

Bos, E., Owen, L., (2016). Virtual reconnection: The online spaces of alternative food networks in England. Journal of Rural Studies 45, pp. $1-14$.

Bosona, T., Gebresenbet, G., Nordmark, I., Ljungberg, D., (2011). Box-Scheme Based Delivery System of Locally Produced Organic Food: Evaluation of Logistics Performance. Journal of Service Science and Management 4, pp. 357-367

Bourlakis, M. A., \& Weightman, P. W. (Eds.). (2004). Food supply chain management. Blackwell Publishing Ltd., Oxford, UK

Brinkley, C., (2017). Visualizing the social and geographical embeddedness of local food systems. Journal of Rural Studies 54, pp. $314-325$.

Brown, A., (2001). Counting farmers markets. Geographical Review 91 (4), pp. 665 - 674.

Brown, E., Dury, S., Holdsworth, M., (2009). Motivations of consumers that use local, organic fruit and vegetable box schemes in Central England and Southern France, Appetite 53, pp. $183-188$

Coley, D., Howard, M., Winter, M., (2009). Local Food, Food Miles and Carbon Emissions: A Comparison of Farm Shop and Mass Distribution Approaches. Food Policy 34 (2), pp. $150-155$.

Corrigan, M. P., (2011). Growing what you eat: developing community gardens in Baltimore, Maryland. Applied Geography 31 (4), pp. $1232-1241$.

Daftary-Steel, S.; Herrera, H.; Porter, C., (2015). The Unattainable Trifecta of Urban Agriculture. Journal of Agric. Food Syst. Community Dev. 6, pp. $19-32$.

Dansero E., Puttilli, M., (2014). Multiple territorialities of alternative food networks: six cases from Piedmont, Italy. Local Environment. International Journal of Justice and Sustainability 19, pp. $626-643$.

Department for Environment, Food and Rural Affairs (DEFRA). (2002). The strategy for sustainable food and farming, facing the future. London: DEFRA.

Dowler, E., Kneafsey, M., Cox, R., (2010). "Doing food differently": reconnecting biological and social relationships through care for food. The Sociological Review 57 (2), pp. $200-221$.

Edwards-Jones G (2010) Does eating local food reduce the environmental impact of food production and enhance consumer health? Proceedings of the Nutrition Society 69 (4), pp. $582-591$.

Engelseth, Per, (2015), Customer-Responsive Supply of Local Foods. Operations and Supply Chain Management 8 (3), pp. $111-119$.

FAO, 2019. The State of Food Security and Nutrition in the World 2019. Safeguarding against economic slowdowns and downturns. Rome, FAO.

Feagan R., (2007), The place of food: Mapping out the 'local' in local food systems. Progress in Human Geography 31, pp. 23 -42 .

Feenstra, G., (1997). Local food systems and sustainable communities. American Journal of Alternative Agriculture 12 (1), pp. $28-36$.

Feldmann, C.; Hamm, U., (2015). Consumers' Perceptions and Preferences for Local Food: A Review. Food Qual. Preference 40, pp. 152 - 164.

Fendrychová, L., Jehlicka, P., (2018) Revealing the hidden geography of alternative food networks: The travelling concept of farmers' markets. Geoforum 95, pp. $1-10$.

Figueroa-Rodríguez, K. A., Álvarez-Ávila, M. C, Hernández Castillo, F., Schwentesius Rindermann, R., FigueroaSandoval, B., (2019). Farmers' Market Actors, Dynamics, and Attributes: A Bibliometric Study. Sustainability 11 (745), pp. $1-15$.

Freedman, D. A., Bell, B. A., Collins, L. V., (2011). The Veggie Project: a case study of a multi-component farmers' market intervention. Journal of Primary Prevention 32 (3-4), pp. 213 -224 .

Freidberg, S., Goldstein, L., (2011). Alternative food in the global south: Reflections on a direct marketing initiative in Kenya. Journal of rural studies 27 (1), pp. $24-34$

Galli, F., Brunori, G. (eds.), (2013). Short Food Supply Chains as drivers of sustainable development. Evidence Document. Document developed in the framework of the FP7 project FOODLINKS (GA No. 265287). Laboratorio di studi rurali Sismondi, pp. 1- 92.

Gascón, J., (2018). Food waste: a political ecology approach. Journal of Political Ecology 25, pp. 587 - 601.

Gracia, A., Magistris, T., Nayga, R. M. Jr., (2012). Importance of social influence in consumers' willingness to pay for local food: Are there gender differences? Agribusiness, An International Journal 28 (3), pp. $361-371$.

Grunert, K.G. (2006). How changes in consumer behaviour and retailing affect competence requirements for food producers and processors. Economía Agraria y de los Recursos Naturales 6 (11), pp. 3 - 22.

Gumirakiza, J.D.; Curtis, K.R.; Bosworth, R., (2014). Who attends farmers' markets and why? Understanding consumers and their motivations. Int. Food Agribus. Manag. Rev. 17, pp. 65 -82 .

Hempel, C., Hamm, U., (2016). How important is local food to organic-minded consumers? Appetite 96, pp. $309-318$.

Hendrickson, M.K., Heffernan,W.D., (2002). Opening Spaces through Relocalization: Locating Potential Resistance in the Weaknesses of the Global Food System. Social Rural 42, pp. $347-369$.

Hinrichs C.C., (2000). Embeddedness and local food systems: Notes on two types of direct agricultural market. Journal of Rural Studies 16, pp. 295 - 303.

Hofmann, C.; Dennis, J.H.; Marshall, M., (2009). Factors influencing the growth of farmers' markets in Indiana. HortScience 44, pp. $712-716$.

Horst, M., Ringstrom, E., Tyman, S., Ward, M., Werner, V., Born, B., (2016). Toward a more expansive understanding of food hubs. Journal of Agric. Food Syst. Community Dev. 2 (1), pp. $209-225$.

Howard, P.H., (2009). Consolidation in the North American organic food processing sector, 1997 to 2007. International Journal of Sociology of Agriculture and Food 16 (1), pp. 13 -30 .

Ilbery, B., Maye, D., (2005). Alternative (shorter) food supply chains and specialist livestock products in the Scottish English borders. Environ. Plan. A 37, pp. 823 - 844.

Jonkman, J., Barbosa-Póvoa, A. P., \& Bloemhof, J. M., (2019). Integrating harvesting decisions in the design of agro-food supply chains. European Journal of Operational Research 276, pp. $247-258$.

Jarosz, L., (2008). The city in the country: growing alternative food networks in metropolitan areas. Journal of Rural Studies 24, pp. $231-244$.

Kirwan, J., (2006). The interpersonal world of direct marketing: examining conventions of quality at UK Farmers' Markets. Journal of Rural Studies 22 (3), pp. $301-312$.

Kneafsey, A.M.; Venn, L.; Schmutz, U.; Balázs, B.; Trenchard, L.; Eyden-Wood, T.; Sutton, G.; Blackett, M.; Santini, E.F.; Gomez, S. (2013), Short Food Supply Chains and Local Food Systems in the EU. A State of Play of Their Socio-Economic Characteristics, EUR-Scientific and Technical Research Series; Publications Office of the European Union: Luxembourg.

Kortwright, R., Wakefield, S., (2011). Edible backyards: a qualitative study of household food growing and its 
contributions to food security. Agriculture and Human Values 28(1), $39-53$.

Kroma, M. M., (2006). Organic Farmer Networks: Facilitating Learning and Innovation for Sustainable Agriculture. Journal of Sustainable Agriculture 28 (4), pp. 5 - 28.

Levidow, L., Psarikidou, K., (2011). Food relocalization for environmental sustainability in Cumbria, Sustainability 3, pp. $692-719$.

Mahajan, R., Garg, S., \& Sharma, P. B. (2017). Processed food supply chain: a framework for literature review. Journal of Advances in Management Research, 14(1), pp. 91-109.

Manikas, I., Malindretos, G., Moschuris, S., (2019). A CommunityBased Agro-Food Hub Model for Sustainable Farming. Sustainability 11 (1017), pp. 1-17.

Marsden T. K., (1998). New rural territories: regulating the differentiated rural spaces. Journal of Rural Studies 14(1), pp. 107.

Marsden, T. K., Banks, J., Bristow, G., (2000). Food supply chain approaches: exploring their role in rural development. Sociologia Ruralis 40, pp. $424-438$.

Marsden, T., Smith, E., (2005). Ecological Entrepreneurship: Sustainable Development in Local Communities through Quality Food Production and Local Branding. Geoforum 36 (4), pp. $440-451$.

Martinez, S., Hand, M., Da Pra, M., Pollack, S., Ralston, K., Smith, T., Vogel, S., Clark, S., Lohr, L., Low, S., (2010). Local Food Systems: Concepts, Impacts, and Issues. Economic Research Report 97; United States Department of Agriculture (USDA): Washington, DC, USA.

Mittal, A., Krejci, C., \& Craven, T. (2018). Logistics best practices for regional food systems: A review. Sustainability, 10(1), pp. 168.

Murdoch, J., Marsden, T., Banks, J., 2000. Quality, nature and embeddedness: some theoretical considerations in the context of the food sector. Economic Geography 72 (6), pp. 107-125.

Nie, J.., Zhang, J., (2017). Distribution channel selection considering advertising productiveness. Journal of Management Mathematics 28, pp. 437 - 450.

O'Neill, K. J. (2014). Situating the 'alternative' within the 'conventional' e local food experiences from the East Riding of Yorkshire, UK. Journal of Rural Studies 35, pp. 112 - 122.

Onwuegbuzie, A. J., Frels, R., (2016). Seven Steps to a Comprehensive Literature Review. A Multimodal and Cultural Approach, $1^{\text {st }}$ Edition, SAGE Publications Ltd, UK.

Pardillo Baez, Y., Sequeira, M., Hilletofth, P., \& Andersson, R. (2019). Local Distribution of Organic Food: A Review and Research Agenda. In Proceedings of the 9th International Conference on Operations and Supply Chain Management (OSCM), Ho Chi Minh City, Vietnam.

Renting, H., Marsden, T. K., Banks, J., (2003). Understanding alternative food networks: exploring the role of short food supply chains in rural development. Environment and Planning A 35 (3), pp. 393 - 411.

Renting, H., Schermer, M., Rossi, A., (2012). Building food democracy: exploring civic food networks and newly emerging forms of food citizenship. International Journal of Sociology of Agriculture and Food 19, pp. 289 - 307.

Ruelas, V., Iverson, E., Kiekel, P., Peters, A., (2012). The role of farmers' markets in two low income, urban communities. Journal of Community Health 37 (3), pp. 554 - 562.

Schmidhuber, J., \& Tubiello, F. N. (2007). Global food security under climate change. Proceedings of the National Academy of Sciences 104 (50), pp. 19703 - 19708.

Siegner, A., Sowerwine, J., Acey, C., (2018). Does Urban Agriculture Improve Food Security? Examining the Nexus of Food Access and Distribution of Urban Produced Foods in the United States: A Systematic Review. Sustainability 10 (2988), pp. $1-27$.

Smithers, J., Johnson, P., (2004). The Dynamics of Family Farming in North Huron County, Ontario. Part I. Development Trajectories. Can. Geogr. 48, pp. $191-208$.

Snyder, H., (2019). Literature review as a research methodology: An overview and guidelines. Journal of Business Research 104 , pp. $333-339$.

Timpanaro, G., Foti, V. T., Scuderi, A., Schippa, G., \& Branca, F., (2018). New food supply chain systems based on a proximity model: the case of an alternative food network in the Catania urban area. Acta Horticulturae 1215, pp. 213 - 218.

Tregear, A., (2011). Progressing knowledge in alternative and local food networks: Critical reflections and a research agenda. Journal of Rural Studies 27, pp. 419 - 430.

Tsolakis, N. K., Keramydas, C. A., Toka, A. K., Aidonis, D. A., \& Iakovou, E. T., (2014). Agrifood supply chain management: A comprehensive hierarchical decision- making framework and a critical taxonomy. Biosystems Engineering 120 (0), pp. $47-64$

UN Department of Economics and Social Affairs, 2015. World population projected to reach 9.7 billion by 2050, New York, USA.

UNSD, 2016. "Sustainable Development Goals Report", retrieved from https://unstats.un.org/sdgs/report/2016/.

Venn, L.; Kneafsey, M.; Holloway, L.; Cox, R.; Dowler, E.; Tuomainen, H., (2006). Researching European 'alternative' food networks: some methodological considerations. Area 38 (3), pp. $248-258$.

Wittman, H., Beckie, M., Hergesheimer, C., (2012). Linking local food systems and the social economy? Future roles for farmers' markets in Alberta and British Columbia. Rural Sociology 77 (1), pp. $36-61$.

Yue, C., Tong, C., (2009). Organic or local? Investigating consumer preference for fresh produce using a choice experiment with real economic incentives. HortScience 44 (2), pp. 366 - 371.

Yinef Pardillo Baez (PhD) is an Assistant Professor of Operations and Supply Chain Management at Jönköping University in Sweden. Her research focuses on supply chain integration, integration-nodes, food supply chains, and sustainable alternative food networks. She has published in international journals and international peer-reviewed conferences.

Movin Sequeira (MSc) is a PhD Student at Jönköping University in Sweden. His research interest includes manufacturing relocation, decision support and sustainable production. He has an M.Sc. degree in Production Development and Management from Jönköping University. He completed his Bachelors in Mechanical Engineering from NMAM Institute of Technology, India. He has published in international peer-reviewed conferences such as EurOMA, IPSERA and ICESDP.

Per Hilletofth (PhD) is a Professor of Operations and Supply Chain Management at Jönköping University in Sweden. His research focuses on demand-supply integration, operations strategy, supply chain relocation, product development, and decision support. He has editorial assignments in several international journals. 